\title{
Novel potential synthetic compounds from thiazolidin-4-one for infectious diseases
}

Incidence and mortality from infectious diseases have increased during the past decade. One of the main reasons is the drug resistance of bacteria, which leads to the appearance of the so-called "superbugs" (i.e., bacteria with extensive or total resistance to commonly used antibiotics). These superbugs, are mostly generated from normal strains of bacteria, including Pseudomonas aeruginosa [1], Helicobacter pylori [2], and methicillin-resistant Staphylococcus aureus (MRSA) [3]. Dangerously, they have spread worldwide, from the USA [4] and Canada [5] to India [6]. Hence, the search for new antibiotics is vital.

In this issue, Pham et al. [7] report the synthesis of 12 new compounds derived from thiazolidin-4-one, followed by evaluation of their antimicrobial activity. Their article, "Antimicrobial activity of some novel 2-(2-iodophenylimino)5-arylidenethiazolidin-4-one derivatives", describes a simple method to synthesize antibacterial molecules with high yields $(>50 \%)$ for all compounds. The chemical structures of these compounds have been elucidated by the authors using spectroscopic methods, including infrared spectroscopy, mass spectrometry, and nuclear magnetic resonance. Although no compounds show antifungal activity against Candida albicans and Aspergillus niger, some of them exhibit remarkable antibacterial effects on both $S$. aureus and MRSA, with the minimum inhibitory concentration (MIC) being as low as $4 \mu \mathrm{g} / \mathrm{mL}$. These compounds can be further studied in terms of their cytotoxicity, using animal tests in vivo, as a prelude to their evaluation in the clinic as candidate drugs for the treatment of infectious diseases.
Although well conducted, there are some limitations to the present work. The synthesis is a multistep process, which makes it difficult for industrial scale-up. Moreover, the types of bacteria tested were limited to 5 strains.

\section{References}

[1] Breidenstein EB, de la Fuente-Núñez C, Hancock RE. Pseudomonas aeruginosa: all roads lead to resistance. Trends Microbiol. 2011; 19:419-26.

[2] Abadi ATB. Helicobacter pylori: emergence of a superbug. Front Med (Lausanne). 2014; 1:34. doi:fmed.2014.00034.

[3] Hawkes M, Barton M, Conly J, Nicolle L, Barry C, Ford-Jones EL. Community-associated MRSA: superbug at our doorstep. CMAJ. 2007; 176:54-6.

[4] Centers for Disease Control and Prevention. Antibiotic resistance threats in the United States, 2013. CDC. 2013; 15-7.

[5] Moellering RC Jr. The growing menace of community-acquired methicillin-resistant Staphylococcus aureus. Ann Intern Med. 2006; 144:368-70.

[6] Nazir T, Abraham S, Islam A. Emergence of potential superbug Mycobacterium tuberculosis, lessons from New Delhi mutant-1 bacterial strains. Int J Health Sci (Qassim). 2012; 6:87-94.

[7] Pham DT, Vo TMH, Truong P, Ho PT, Nguyen MQ. Antimicrobial activity of some novel 2-(2-iodophenylimino)-5-arylidenethiazolidin-4-one derivatives. Asian Biomed (Res, Rev, News). 2017; 11:405-12.

*Correspondence to: Editorial Office of Asian Biomedicine, Faculty of Medicine, Chulalongkorn University, Bangkok 10330, Thailand, e-mail: abmjournal@chula.ac.th

¿ Open Access. (c) 2017 Editorial Office of Asian Biomedicine, published by Sciendo. (c) BY-NC-ND This work is licensed under the Creative Commons Attribution NonCommercial-NoDerivatives 4.0 License. 